\title{
Band GAP Frequency Response in Regular Phononic Crystals
}

\begin{abstract}
SEBASTIAN GARUS ${ }^{*}$, MICHAL SZOTA ${ }^{2}$
${ }^{1}$ Institute of Mechanics and Fundamentals of Machinery Design, Faculty of Mechanical Engineering and Computer Science, Czestochowa University of Technology, 19 Armii Krajowej Str., 42-200 Czêstochowa, Poland

${ }^{2}$ Institute of Materials Engineering, Faculty of Production Engineering and Materials Technology, Czestochowa University of Technology, 19 Armii Krajowej Str., 42-200 Czêstochowa, Poland

The studyinvestigated the propagation of a mechanical wave in a two-dimensional phononic structure. The influence of material from which metaatom rods were made on the phononical properties of the structure was investigated. Rods made of amorphous $\mathrm{Zr}_{55} \mathrm{Cu}_{30} \mathrm{Ni}_{5} \mathrm{Al}{ }_{10}$ and polypropylenes were compared. The Finite Difference Time Domain (FDTD) algorithm was used to carry out the simulation. Next, theoretical and experimental analysis of the intensity of the mechanical wave was carried out. Frequency response of a regular phononic structure was also analyzed.
\end{abstract}

Keywords: phononic crystal, FDTD, DFT, acoustic

In many research centers, the properties of photonic [16] and phononic [7-10] structures are analyzed, in which respectively electromagnetic and mechanical waves are propagated. Both these fields show a large similarity despite the description of various types of phenomena. In phononic crystals, depending on the type of the structure being designed, phononical band gap may occur. This phenomenon consists in the lack of wave propagation ata given frequency in the phononic crystal. Depending on the metaatoms distribution in the structure and its shape, it is possible to obtain different types of wave propagation [1115]. There are three types of phononic crystals depending on the dimension of the analyzed space: one- (1D), two(2D) and three-dimensional (3D). Phononic crystals can be used to suppress noise as selective filters [16, 17], or to direct the beam in acoustic devices to extinguish flames [18].

For phononic crystals with a periodic structure and a large number of metaatoms, it is possible to obtain a band structure and bandgaps using Finite Element Method algorithm - what the majority of research focuses on [1921]. Practical implementations of phononic crystals are characterized by not very large number of metaatomes and there may be defects in the structure execution. In simulations of such structures, the Finite Difference Time Domain (FDTD) algorithm works perfectly well, although it is characterized by high time complexity of calculations. FDTD is used for all types of space dimensions: 1D [9], 2D and $3 \mathrm{D}[22,23]$.

\section{Two-dimensional FDTD}

The propagation of a mechanical wave can be represented by a system of equations

$$
\left\{\begin{array}{c}
\frac{1}{\rho c^{2}} \frac{\partial P}{\partial t}=-\nabla \cdot \vec{v} \\
\rho \frac{\partial \vec{v}}{\partial t}=-\nabla P
\end{array}\right.
$$

where: $P\left[\mathrm{~kg} / \mathrm{m} \cdot \mathrm{s}^{2}\right]$ is the pressure field and $\vec{v}[\mathrm{~m} / \mathrm{s}]$ is the vector field of phase velocity, $\rho\left[\mathrm{kg} / \mathrm{m}^{3}\right]$ is the mass density, and $c$ is phase velocity propagated in the material.

Equation (1) can be written as:

$$
\left\{\begin{array}{l}
\frac{\partial P}{\partial t}=\rho c^{2}\left(\frac{\partial v_{x}}{\partial x}+\frac{\partial v_{y}}{\partial y}+\frac{\partial v_{z}}{\partial z}\right) \\
\frac{\partial v_{x}}{\partial t}=\frac{1}{\rho} \frac{\partial P}{\partial x} \\
\frac{\partial v_{y}}{\partial t}=\frac{1}{\rho} \frac{\partial P}{\partial y} \\
\frac{\partial v_{z}}{\partial t}=\frac{1}{\rho} \frac{\partial P}{\partial z}
\end{array}\right.
$$

What for the two-dimensional case takes the form:

$$
\left\{\begin{array}{l}
\frac{\partial P}{\partial t}=-\rho c^{2}\left(\frac{\partial v_{x}}{\partial x}+\frac{\partial v_{y}}{\partial y}\right) \\
\frac{\partial v_{x}}{\partial t}=-\frac{1}{\rho} \frac{\partial P}{\partial x} \\
\frac{\partial v_{y}}{\partial t}=-\frac{1}{\rho} \frac{\partial P}{\partial y}
\end{array}\right.
$$

After discretization of space to points addressed with indices $(i, j)$ with a lattice constant $\Delta z$ and the conversion of derivatives into differences the pressure value $P^{n+1}(i, j)$ for a given time moment $n+1$ from formula (3) depends on the previous pressure value $P^{n}(i, j)$ (where timestep is defined as $\Delta t$ ) according to the formula:

$$
\begin{aligned}
& P^{n+1}(i, j)=P^{n}(i, j)-\rho(i, j)(c(i, j))^{2} \frac{\Delta t}{\Delta z} . \\
& \cdot\left[v_{x}^{n+1 / 2}(i, j)-v_{x}^{n+1 / 2}(i-1, j)+\right. \\
& \left.+v_{y}^{n+1 / 2}(i, j)-v_{y}^{n+1 / 2}(i, j-1)\right]
\end{aligned}
$$

The vector field of the phase velocity was determined according to the formulas:

$$
\begin{aligned}
& v_{x}^{n+1 / 2}(i, j)=v_{x}^{n-1 / 2}(i, j)-\frac{\Delta t}{\Delta z \rho(i, j)} . \\
& \cdot\left[P^{n}(i+1, j)-P^{n}(i, j)\right] \\
& v_{y}^{n+1 / 2}(i, j)=v_{y}^{n-1 / 2}(i, j)-\frac{\Delta t}{\Delta z \rho(i, j)} . \\
& \cdot\left[P^{n}(i, j+1)-P^{n}(i, j)\right]
\end{aligned}
$$

\footnotetext{
*email: gari.sg@gmail.com
} 
In order to obtain stable simulation results, it is important that the Courant's stability condition is maintained between the steps in space and time:

$$
\Delta t<\frac{1}{c_{\max } \sqrt{\frac{1}{(\Delta x)^{2}}+\frac{1}{(\Delta y)^{2}}}}
$$

For a constant step in both directions $(\Delta z=\Delta x=\Delta y)$ we get:

$$
\Delta t<\frac{1}{c_{\max } \sqrt{\frac{2}{(\Delta z)^{2}}}}=\frac{\Delta z}{c_{\max } \sqrt{2}}
$$

PML algorithm was used to extinguish the wave, and the power spectrum was obtained using Discrete Fourier Transform.

Figure 1 presents the analyzed measurement system. The mechanical wave coming from the source falls on the structure of the phononic crystal made of rods. Inside the structure, there is interference and diffraction of the propagating wave and then it goes to the detector.

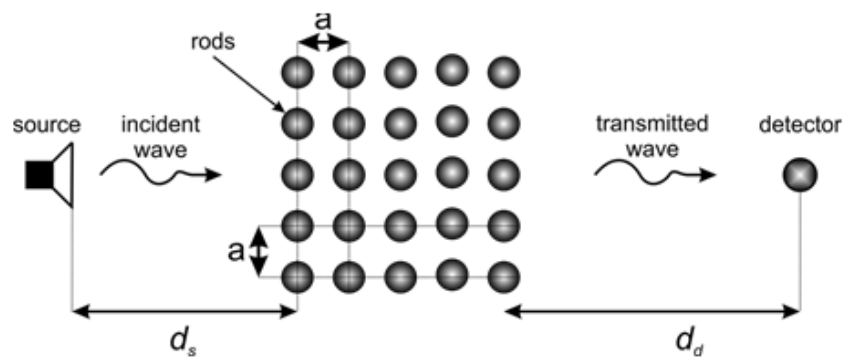

Fig. 1. Diagram showing simulation and experiment

The first Bragg band gap central frequency $f_{c}$ of the regular structure [24, 25] is given by:

$$
f_{c}=\frac{c_{a}}{2 a}
$$

where $c$ is sound velocity in the air and $a$ is the lattice parameter.

\section{Research}

The work analyzed the structure of a regular phononic crystal with metaatoms made of rods with a diameter $r$ of $25 \mathrm{~mm}$, distributed in a space with a lattice constant a equal to $40 \mathrm{~mm}$. In order to check the influence of the type of material from which the sonic crystal was made on the propagation of a mechanical wave, simulation was carried out for two types of materials. Polypropylene was the first choice due to its low cost and high availability [26]. The second material was an $\mathrm{Zr}_{55} \mathrm{Cu}_{30} \mathrm{Ni}_{5} \mathrm{Al}_{10}$ amorphous alloy. This type of alloys, due to their microstructure, are characterized by interesting phononic properties [27], although they are most often used in industry for their unique magnetic properties [28-36]. The whole structure is surrounded by air. The material properties used in the simulation were collected in table 1.

The distance between the source of mechanical waves and the sonic crystal was $d_{s}=30 \mathrm{~cm}$, the thickness of the structure $18.5 \mathrm{~cm}$. In the simulation, the first detector (D1)

Table 1

MATERIAL PROPERTIES USED IN CALCULATIONS [26, 27]

\begin{tabular}{|l|c|c|}
\hline Material & $\begin{array}{c}\text { Mass density } \\
\boldsymbol{\rho}\left[\mathrm{kg} / \mathbf{m}^{\mathbf{3}}\right]\end{array}$ & $\begin{array}{c}\text { Velocity of sound } \\
\mathbf{v}[\mathrm{m} / \mathrm{s}]\end{array}$ \\
\hline Air & 1.29 & 331.45 \\
\hline Polypropylene & 900 & 1450 \\
\hline Zr55Cu30NisAl]0 & 6829 & 1633 \\
\hline
\end{tabular}

was placed $4 \mathrm{~cm}$ in front of the crystal and the other (D2) $d_{d}=10 \mathrm{~cm}$ behind the structure. The central frequency of the first Bragg band gap for this structure from equation 9 is $4143 \mathrm{~Hz}$. The step in space was set to $\Delta z=5 \mathrm{~mm}$, while in time it was $\Delta t=1.67 \cdot 10^{-6} \mathrm{~s}$ from Courant condition (eq. 8). Perfect Match Layers (PML) algorithm was responsible for extinction of the wave leaving the simulation, the number of layers was 8 . The total time of each simulation was $8.33 \mathrm{~ms}$, which consisted of 5000 time steps. Simulation for figures 2, 3 and 4 uses a soft source with a frequency of $4.1 \mathrm{kHz}$. Figure 1 shows the time series of the pressure amplitude obtained at points D1 and D2. It should be noted that the values for a structure made of an amorphous alloy (solid line) are closely related to the values obtained for polypropylene (dotted line). Figure 3 shows the difference between these values.

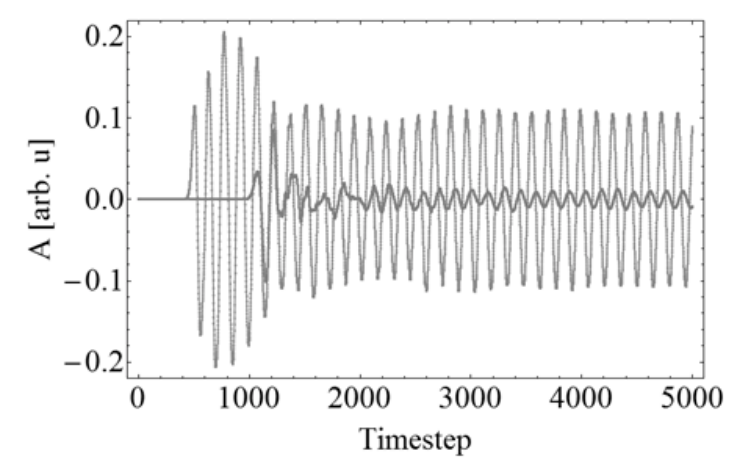

Fig. 2. Distribution of pressure amplitude A over time (source frequency equal to $4.1 \mathrm{kHz}$ ) at points D1 and D2. The lines and points are respectively marked for a simulation of phononic crystal composed of an amorphous alloy and polypropylene.

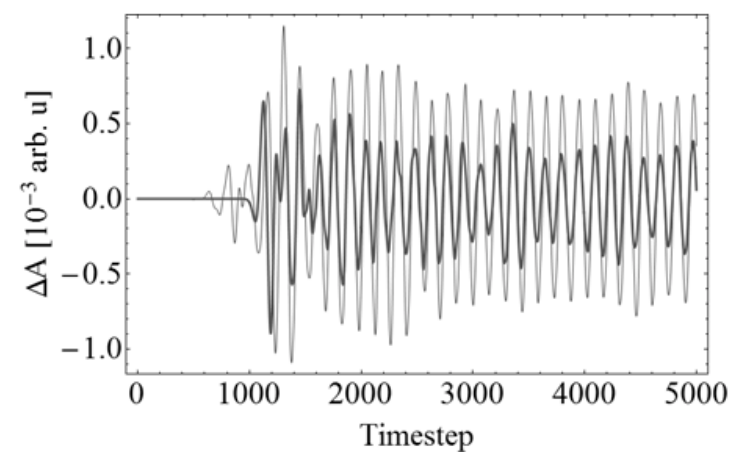

Fig. 3. Difference in pressure amplitudes for a crystal made of amorphous alloy to made of polypropylene in points D1 and D2.

As can be seen in figure 4, the type of material did not affect to the signal power spectrum.

On the basis of the obtained results, it should be assumed that the type of material from which the sonic crystal was made has a small influence on the propagation of the mechanical wave in the structure. Therefore, the remaining analysis was carried out using polypropylene.

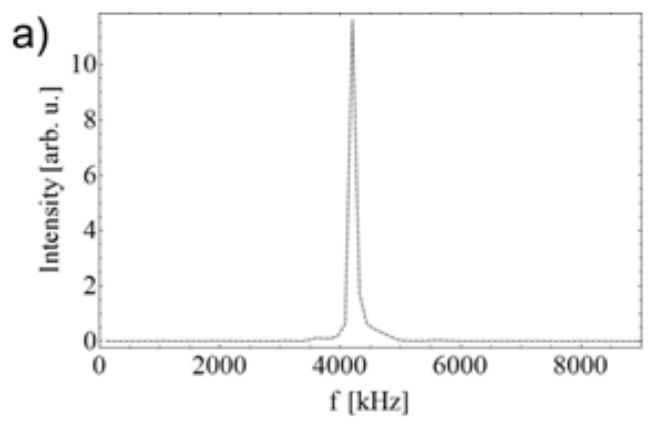

Fig. 4a. Power spectrum of pressure time series in points D1 
b)

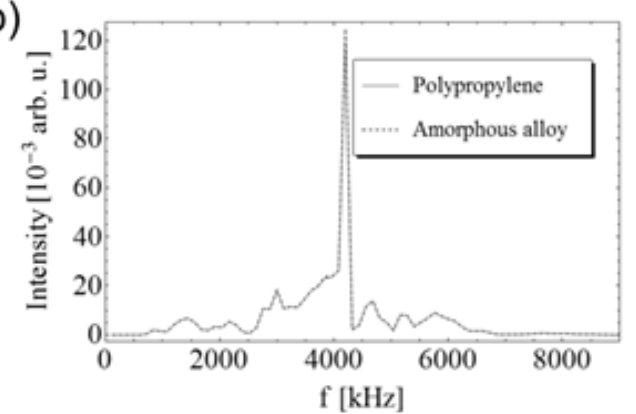

Fig. 4b. Power spectrum of pressure time series in points D2

Then, the simulation results were compared with the experiment. Figure 5 shows the time series at point D2 for different source frequencies. It should be noted a significant reduction of the amplitude near the first band gap Bragg central frequency. Experimental data (fig. 6) confirm the occurrence of a band gap by a significant reduction of the mechanical wave intensity near $4.1 \mathrm{kHz}$. The frequency response behind the phononic crystal structure at pointD2 was analyzed for the source frequency range from $3.5 \mathrm{kHz}$ to $4.7 \mathrm{kHz}$ at $100 \mathrm{~Hz}$ (fig. 7). In the power spectrum graph, additional peaks can be seen around the source frequency distant from the main peak at $100 \mathrm{~Hz}$. As a detector in the experiment, the Norsonic Nor140 sound analyser was used with built-in FFT mode.
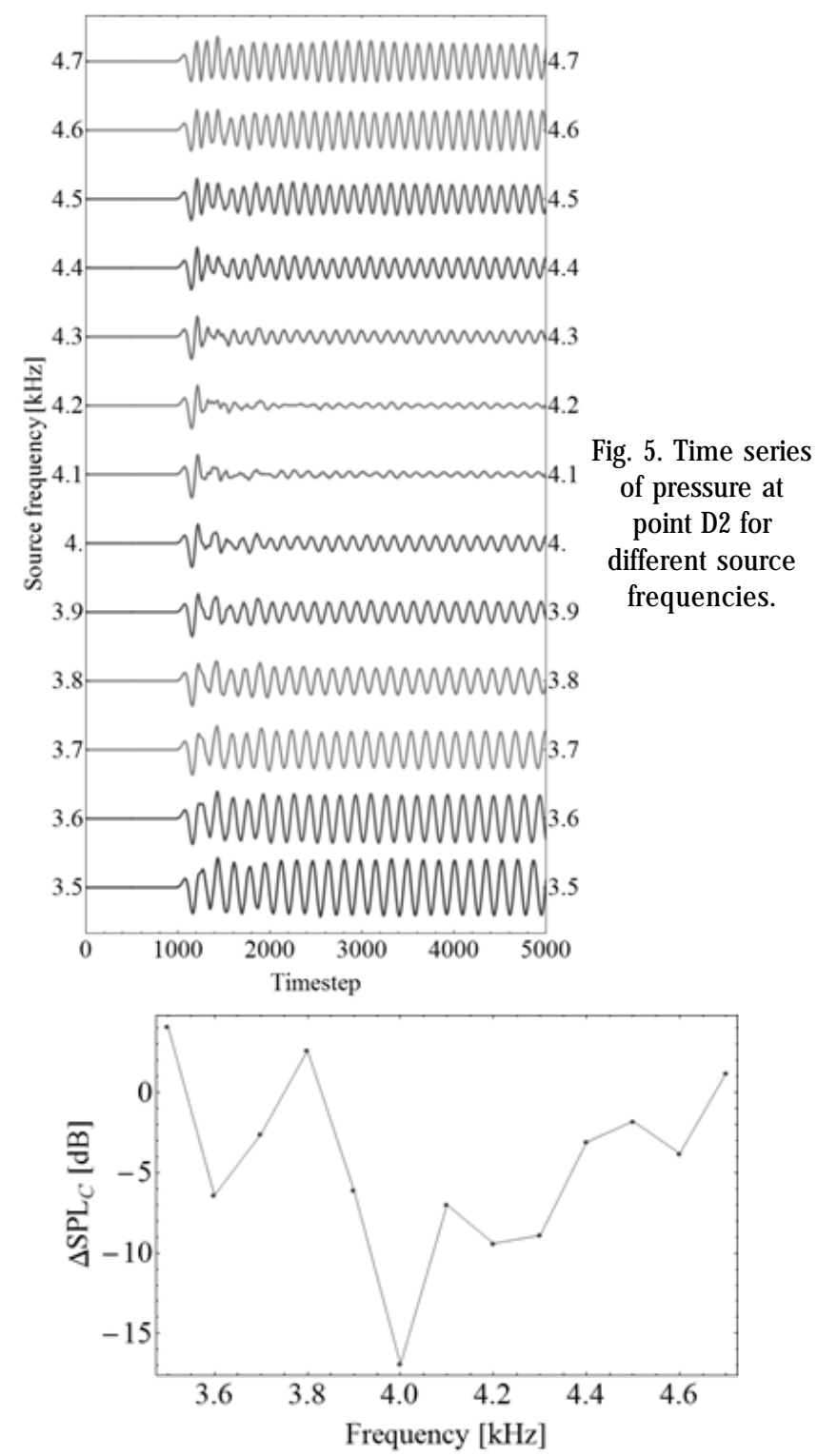

Fig. 6. Experimental $\mathrm{SPL}_{\mathrm{C}}$ change in relation to the measuring system without structure.

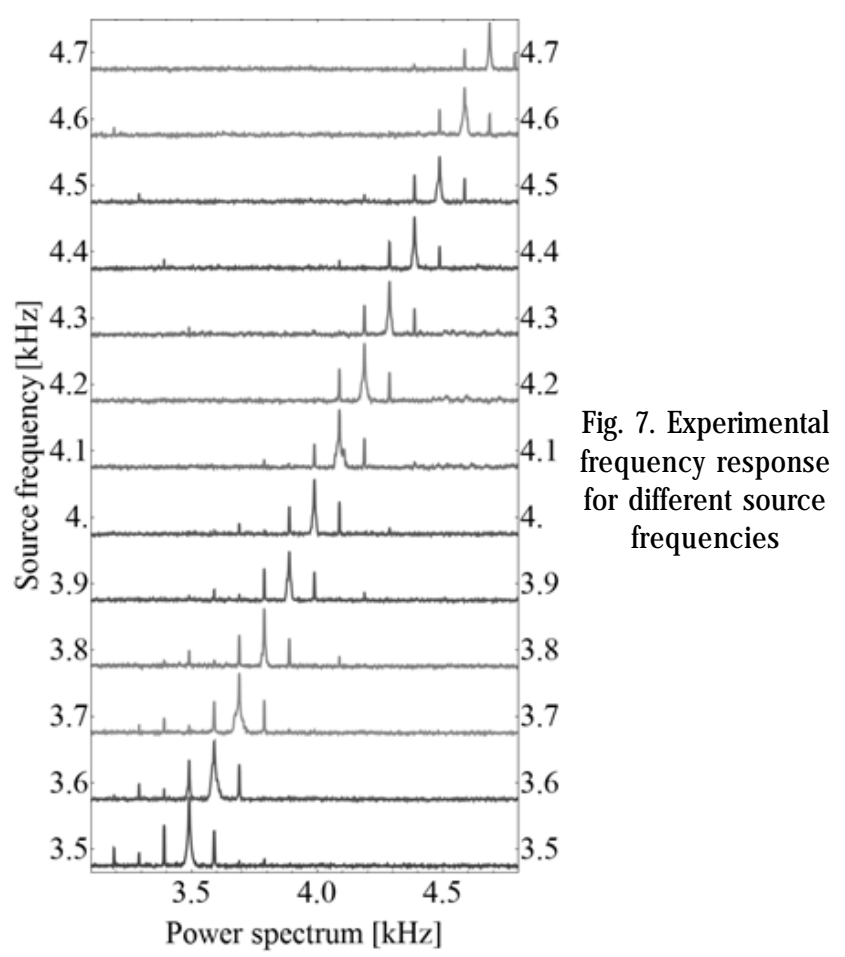

\section{Conclusions}

The work analyzed propagation of the mechanical wave in the phononic structure. The simulation carried out using the FDTD algorithm showed a negligible influence of the material type from which metaatoms are made on mechanical wave propagation in the structure. In the simulation, as in the experiment, the occurrence of a band gap for $4.1 \mathrm{kHz}$ frequency was observed. In the power spectrum of the experimental system, the source frequency was observed, but with much lowers intensity.

\section{References}

1.BOUFENAR R., BOUAMAR M., HOCINI A., Chinese J ournal of Physics, 56, nr. 3, 2018, p. 1126-1132

2.ZHANG L., LIU B., WANG J., TAO S., YAN Q., J ournal of Colloid and Interface Science, 509, 2018, p. 318-326

3.SZOTA M., NABIALEK M., GARUS S., GARUS J., K. BLOCH, Archives of Materials Science and Engineering 64, 2, 2013, pp. 213-218 4.GARUS S., GARUS J ., SZLYZAK K., NABIALEK M., PIETRUSIEWICZ P., BLOCH K., GRUSZKA K., SZOTA M., Journal of Achievements in Materials and Manufacturing Engineering, 61, nr. 2, 2013, p. 236-243 5.GARUSS., GARUS J ., NABIAfEK M., GRUSZKA K., B£OCH K., Archives of Materials Science and Engineering, 64, nr. 2, 2013, p. 110-117 6.SZOTA, M., Rev.Chim. (Bucharest), 69, no. 1, 2018, p. 166-168 7.LU Y., SRIVASTAVA A., J ournal of the Mechanics and Physics of Solids, 111, 2018, p. 100-112

8.GARUS, S., SZOTA, M., Rev.Chim. (Bucharest), 69, no. 3, 2018, p. $735-738$

9.GARUS, S., SOCHACKI, W., J ournal of Applied Mathematics and Computational Mechanics, 16, nr. 4, 2017, p. 17-27

10.GARUS, S., SOCHACKI W., BOLD M., Engineering Mechanics 2018 (red.) FISCHER Cyril, NAPRSTEK Jiri, Institute of Theoretical and Applied Mechanics of the Czech Academy of Sciences, Prague, 2018, p. 229-232

11.LU M. H., FENG L., CHEN Y. F., Mater. Today, 12, nr. 12, 2009, p. 3442

12.BUZEA, C.G., BEJ INARIU, C., BORIS, C., VIZUREANU, P., AGOP, M., International J ournal of Nonlinear Sciences And Numerical Simulation, 10, no. 11-12, 2009, p. 1399.

13.MINCIUNA, M.G., VIZUREANU, P., ACHITEI, D.C., GHIBAN, B., SANDU, A.V., MARECI, D., BALAN, A., Rev.Chim. (Bucharest), 65, no. 10, 2014, p 1138-1141. 
14.ACHITEI, D., GALUSCA, D.G., VIZUREANU, P., CARABET, R., CIMPOESU, N., Metalurgia International, 14, 2009, p. 45

15.NEMES, 0., Studia Universitatis Babes-Bolyai Chemia, 52, no. 4, 2007, p. 175.

16.KRIEGEL I., SCOTOGNELLA F., Physica E, 85, nr. 34, 2017, p. 34-37 17.VILLA-ARANGO S., TORRES R., KYRIACOU P.A., LUCKLUM R., Measurement, 102, nr. 20, 2017, p. 262-269

18.NIEGODAJ EW P., fUKASIAK K., RADOMIAK H., MUSIAL D., ZAJEMSKA M., POSKART A., GRUSZKA K., Combustion and Flame, 194, 2018, p. 245-249

19.LIU Y., SU J.Y., XU Y.L., ZHANG X.C., Ultrasonics, 49, 2009, p. 276280

20.VASSEUR J.O., DJAFARI-ROUHANI B., DOBRZYNSKI L., DEYMIER P.A., J. Phys.: Condens. Matter, 9, 1997, p. 7327-7341

21.ZHONG L., WU F., ZHANG X., ZHONG H., ZHONG S., Phys. Lett. A, 339, 2005, p. 164-170

22.SULLIVAN D.M., Electromagnetic Simulation Using the FDTD Method, IEEE Press, New York 2000.

23.TAFLOVE A., Computational Electrodynamics: The Finite-Difference Time-Domain Method, Artech House Inc., Norwood, MA, 1995 24.KUSHWAHA M. S., HALEVI P., DOBRZYNSKI L., DJAFARI-ROUHANI B., Phys. Rev. Lett., 71, 1993, p. 2022-2025

25.SIGALAS M.M., ECONOMOU E.N., J. Sound Vib. 158, 1992, p. 377382

26.YANG S., YU W.D., PAN N., Physica B: Condensed Matter., 406 2011; p. $963-966$
27.FUKUHARA M., WANG X., INOUE A., J Non-Cryst Solids, 356, 2010, p. $1707-1710$

28.NABIALEK M.G., PIETRUSIEWICZ P., DOSPIAL M.J., SZOTA M., BfOCH K., GRUSZKA K., O•GA K., GARUS S., Journal of Alloys and Compounds, 615, 2014, p. S51-S55

29.GARUS S., NABIALEK M., BLOCH K., GARUS J ., Acta Phys. Pol. A, 126, nr. 4, 2014, p. 957-959

30.GONDRO J., BLOCH K., NABIALEK M., GARUS S., Materials and Technologies, 50, nr. 4, 2016, p. 559-564

31.GARUS J., GARUS S., NABIALEK M., SZOTA M, Acta Phys. Pol. A, 126, nr. 4, 2014, p. 954-956

32.GRUSZKA K., NABIALEK M., SZOTA M., BLOCH K., GONDRO J., PIETRUSIEWICZ P., SANDU A. V., MUSTAFA AL BAKRI A. M., WALTERS S., WALTERS K., GARUS S., DOSPIAL M., MIZERA J ., Arch. Metall. Mater., 61, nr. 2, 2016, p. 641-644

33.BLOCH K., NABIALEK M., DOSPIAL M., GARUS S., Arch. Metall. Mater., 60, nr. 1, 2015, p. 7-10

34.GARUS, S., NABIALEK M., GARUS J ., Acta Phys. Pol. A, 126, nr. 4, 2014, p. 960-962

35.BLOCH K., NABIALEK M., GARUS S., Acta Phys. Pol. A, 130, nr. 4, 2016, p. 905-908

36.NABIALEK M., GARUS S., Acta Phys. Pol. A, 130, nr. 4, 2016, p. 10101012

Manuscript received: 11.09 .2018 